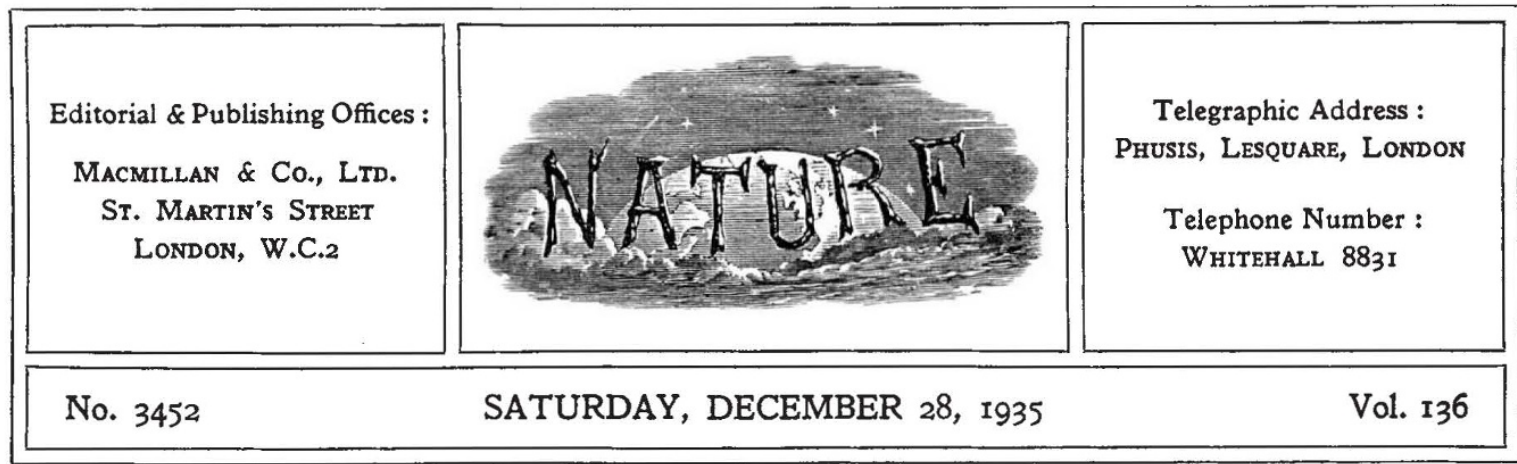

\title{
'Justice' in Africa
}

A $S$ the year draws to its close, the passing of time reminds us of the useful convention whereby we are encouraged to enter upon some sort of a stocktaking preparatory to the closing of the annual account. In such a survey of the past year, the chain of events which has threatened, and still endangers, the peace of the world must be a salient item. Here, however, the very magnitude of the issues involved hampers critical judgment, and while the event is weighed in the scale according as it has made for or against the working of the machine which we call the League of Nations, it may not readily be discerned that 'profit and loss' are not to be assessed in terms of the number of nations declaring their formal adherence to Article xvi, but rather in any real progress towards the universal application of the fundamental principle of justice as between man and man, towards which the League was a gesture of aspiration, as well as an admittedly imperfect piece of machinery for its attainment.

However posterity may apportion blame as between Italy and Abyssinia for breach of the peace - no attempt will be made here to estimate the merits of the dispute- there can be no question that the principle of the League, as well as the letter of its Covenant, has been violated. Should the League fail to vindicate that principle, through it the prestige of white civilisation will be affected throughout Africa.

The admission of Abyssinia to the League is a matter of past history. It is profitless now to discuss whether that admission was justifiable or not. But it would be idle to pretend that she stood upon an equal footing with other members of the League. Admission was an earnest of security in the upward struggle from barbarism to which her rulers were then committed; and this attack on her by a nation of advanced civilisation with all the resources of a modern armament at its command is a breach of an implied pledge of her right to integrity, which no political, diplomatic or economic argument can justify. It is a cynical reversion to the acquisitive methods of the nineteenth century, which led to the partition of Africa among the interested Powers of Europe.

The attack of Italy on Abyssinia, however strong the argument from economic necessity or pressure of population now that other outlets are restricted, is out of harmony with the spirit of the twentieth century. Native races-using the term in a loose conventional sense-can no longer be regarded as 'inferior' and mere raw material for exploitation, whose lands may be developed, regardless of their rights and interests, solely for the benefit of a superior white race. An attitude of mind more nearly in accord with the present trend of scientific study of racial problems demands that the relations between white and black, which are a consequence of the inevitable expansion of European civilisation, should be regulated by an adjustment of the conflicting claims which arise from the clash of two cultures in some respects incompatible but, it is hoped and indeed as experience is showing, not ultimately and entirely irreconcilable. Where white civilisation successfully vindicates its claim to the superior position, it is not as an overriding, but as a tutelary force. The final ruling, for all but areas of overwhelmingly white settlement, was given in the dictum of Lord Passfield's famous White Paper, in which it was declared that "the interests of the native must be paramount". This to the native is his Magna Charta, the warrant on which the 
white administration must justify its control and occasional modification of native custom and belief. This was the spirit which framed the African mandates of the League of Nations ; it is not the spirit or the practice of Italian colonisation, either in Cyrenaica or in north-east Africa. Settlement here is frankly and avowedly Italy overseas, with all that that implies in regard to native interests.

The moral obligation to guard and guide the native in changing conditions is naturally not confined to mandated territory, but rests on all administrations alike. To some critics this obligation seemed in danger recently, when the development of the Kakamega gold mines was under consideration; but in fairness to the Administration of Kenya it has to be admitted that the point at issue did not really arise out of a disregard of the interests of the native, but from a difference of opinion over the question of immediate benefits, especially financial and economic, as opposed to ultimate well-being, which anthropologists and others felt would be jeopardised by the displacement of native holdings, and the cultural disintegration which is inseparable from the opening up of any area in Africa to mining enterprise.

On difficult questions such as those raised by the Kakamega gold mines-questions of frequent occurrence, though not often arousing such widespread interest-much light is thrown by two recent publications dealing with the relation of governors and governed in East Africa. Of these Dr. Thurnwald's "Black and White in East Africa"* is especially valuable for his survey of the whole course of contact between an African tribe and European civilisation from its very beginning. He also examines in great detail the various measures by which the administration deals with every aspect of its native contacts, including its organisation for the improvement of native conditions in both a material and a spiritual sense, while at the same time he gives due heed to all interests, both black and white, involved in the problem.

It is to be noted that Dr. Thurnwald, in concluding, quotes in reference to 'the outlook' the evidence of certain prominent chiefs before a commission in 1932, in which they elaborated an argument that present conditions of education and labour tend to destroy among members of the

* Black and White in East Africa : the Fabric of a New Civilization ; a Study in Social Contact and Adaptation of Life in East Africa. By Richard C. Thurnwald. With a Chapter on Women, by Hilde Thurnwald. Pp. xxii $+419+16$ plates. (London: George Routledge and Sons, Ltd., 1935.) 218. net. younger generation the feeling that they have a stake in the country. This is attributed to the breaking up of the old closely-knit and strongly localised family and tribal ties through these agencies. This view is of importance as a native criticism of such current tendencies as aim at 'civilising' the native. Against it, on the other hand, must be set the view, which appears to be gaining ground in West Africa-naturally among the more advanced members of the native com. munity-that 'indirect rule' and the anthropological approach to administrative problems have been formulated as a principle with the express purpose of retarding the development of the people. Extreme as this view may be, it is unnecessary to stress the importance of its recognition as an element in the problem of which account must be taken, lest the most progressive and intelligent among the natives should be alienated. Those who hold such opinions are not necessarily all discontented or disgruntled agitators.

Even more interesting than Dr. Thurnwald's book in certain respects is an account of an experiment in anthropological and administrative research combined, which was carried out in Tanganyika*. Dr. Gordon Brown, anthropologist, and Mr. Bruce Hutt, District Officer of Iringa, joined forces, and for a year worked in close and continuous co-operation, the administrator posing questions to the anthropologist as they arose in the course of his work, and the anthropologist supplying the answer from material obtained by an investigation made ad hoc among the people on the special point.

The result was illuminating in more directions than one. Most important perhaps for the future of 'indirect rule'- - the Hehe, the tribe under investigation, came under indirect rule in 1926is the clear demarcation of the limits within which the application of anthropological research to administrative problems is practicable; but no less useful was the experience of the manner in which the posing of a question by the administration may open up new lines of thought and research for the anthropologist.

In so far as it is possible to summarise the result of a co-operative effort, of which every detail is worthy of careful consideration by those interested in scientific research and native administration, the work of these authors would go to show that

* Anthropology in Action : an Experiment in the Iringa District of the Iringa Province, Tanganyika Territory. By Dr. G. Gordon Brown and $\mathrm{A}$. McD. Bruce Hutt. (Published for the International Institute of African Languages and Cultures.) Pp. xviii +272. (London : Oxford University Press, 1935.) 78. 6d. net. 
in imposing indirect rule upon the tribes of Tanganyika, the administration builded better than it knew. For investigation of the status quo, which was accepted by the system of indirect rule as guiding principle, as for example in continuing in office the 'headman' of the old regime, has revealed that underlying the outward form were unsuspected ramifications going deeply into social and religious belief and practice, which would have been destroyed and their benefits lost by any change that, to superficial observation, might have seemed to be little more than one in form alone.

The extension of the form, or at least the spirit, of indirect rule in the British areas of administration-the position of the Union of South Africa and the French Colonial system demand separate consideration-is in itself an adequate rejoinder to inquiry as to how stand the backward peoples of Africa there in relation to the principles of which the League of Nations is at present the nearest approach to living expression.

The aim of indirect rule clearly is by means of care for the existing order to make haste slowly. Hitherto, the efforts of those who have the interests of Africa at heart have been directed to protection of the native through the preservation of his institutions; but this at the best is no more than a means to an end, an attempt to control the pace of development, and to avoid too rapid and disastrous breaking up of custom. But lest the native critic be justified, has the time not now come to ask ourselves: What comes next? What is the policy of development that lies behind and gives meaning to 'indirect rule', if it is not to be regarded as entirely static?

If any trust is to be placed in signs of the times, the day is rapidly approaching when some such question will have to be faced; and by the practical wisdom and foresight shown in the event will the answer given by white rule in Africa be judged. We now stand at a point far removed from Kipling's concept of "the 'eathen in 'is blindness", and, to revert to the issue from which we started, the proposals for a compromise in the Abyssinian conflict cannot be allowed to evade responsibility by treating whole territories and peoples, whose future is at stake, as pawns in a game. Fiat justitia, rual coelum, it may be, is no motto for statesmen, who are 'realists'; but, unless the whole stream of history is destined to change its course, it is the acid test which will be applied by posterity. In the interests of world peace, it may be necessary to cede disputed territory, but under conditions which place the interests and well-being of the inhabitants before colonial ambition.

\section{A Himalayan Expedition}

Nanga Parbat Adventure:

a Himalayan Expedition. Translated from the German of Fritz Bechtold by H. E. G. Tyndale. Pp. $\mathrm{xx}+93+80$ plates. (London: John Murray, 1935.) $10 s .6 d$. net.

$\mathrm{T}$ HIS is an account of the German-Austrian expedition of 1934, under the leadership of Willy Merkl, which attempted to climb the Western Himalayan mountain Nanga Parbat. This mountain culminates in a peak $26,620 \mathrm{ft}$. above sea-level-it is the tenth highest in the Himalaya. It rises directly from the Indus valley. Here it is possible to see in a single view from the river bed to the mountain top no less than $23,000 \mathrm{ft}$. of tremendous precipices. We believe this is the greatest amount of slope exposed in the world.

Nanga Parbat has unfortunately acquired an evil reputation. On its slopes in 1895, A. F. Mummery and his two Gurkha companions were lost. In 1932 a German-American expedition, also under the leadership of Willy Merkl, including two members of the expedition under review, failed to reach a greater height than $23,000 \mathrm{ft}$. owing to porter troubles and bad weather. On that occasion, porters were recruited from Nanga Parbat district "and there lay one of the main causes of its failure. Consequently it was decided at home to spare neither trouble nor expense in order to fetch Himalayan 'tigers' from Darjeeling to Kashmir", that is, men who had taken part in the Everest and Kamet expeditions. The original party comprised eight climbers, a group of three scientific workers, a doctor and a camp commandant, with a full complement of porters.

The expedition appears to have been well equipped when it reached the base camp, and both climbers and porters were experienced. Notwithstanding this, it met with the worst disaster that has befallen any Himalayan adventure. Of the advance party of sixteen, no less than nine lost their lives on the mountain-three Europeans, 